\title{
Condicionalidad y Autoría. Sobre la verdadera libertad de los seres humanos
}

\author{
TOMÁS GIL \\ TU Berlín
}

RESUMEN. Ciertas ideas erróneas que solemos asociar con el fenómeno de la libertad son aquí objeto de una crítica que se propone mostrar en qué consiste realmente la libertad de los seres humanos.

\begin{abstract}
Certain ideas we normally tend to have concerning human freedom are here criticized in this paper which tries to show that and how freedom as an activity of self-determination is perfectly compatible with natural determinism.
\end{abstract}

La libertad es sin duda alguna uno de los problemas más difíciles con los que se ve confrontado el pensamiento humano. Cuando hablamos de libertad nos planteamos la cuestión de explicar cómo es posible que, a pesar de todos los factores que parecen determinarnos a distintos niveles, seamos capaces de comprendernos como seres autónomos, como seres libres, que hacen lo que realmente quieren, es decir, que pueden en cierto sentido determinar ellos mismos lo que van a hacer $y$, por tanto, lo que puede ocurrir en el mundo.

Como siempre que tratamos problemas filosóficos serios y difíciles también en este caso nos vemos confrontados con la influencia de ideas o concepciones no adecuadas que hemos ido adquiriendo en el transcurso de nuestras vidas y que vienen a dificultarnos la tarea de comprensión, dado que tales ideas o creencias no adecuadas nos seducen y llevan a pensar aquello que, mirándolo bien, es más obstáculo que salida, es antes problema que una solución.

A continuación me propongo indicar qué ideas serían las más adecuadas en lo concerniente al problema de la libertad humana, es decir, qué ideas nos pueden llevar a comprendernos mejor como seres libres. Esto equivaldría a aclarar el concepto de libertad, si no de manera exhaustiva, sí en parte y con algún efecto práctico. Por otro lado, creo que en esto consiste realmente el quehacer cotidiano de la filosofía: en el esclarecimiento, modesto pero firme, de nuestros conceptos, que en el fondo no son más que ideas configuradas y llevadas a un cierto nivel de precisión.

La aclaración tendrá lugar en dos tiempos. Primero pretendo mostrar que la libertad humana no solamente es compatible con el determinismo, sino que más bien lo presupone. A continuación me concentraré en algunos de 
los distintos mecanismos de autodeterminación en los que consiste realmente la libertad efectiva de los seres humanos: mecanismos que por cierto presentan a menudo un carácter paradójico.

\section{Libertad verdadera}

Cuando filosofamos, tratamos de ver qué es lo que podemos decir con sentido sobre las cuestiones y asuntos que nos interesan. Como muy a menudo nos vemos envueltos, por el uso de nuestro lenguaje cotidiano impreciso, en una maraña de ideas y representaciones no adecuadas, una de las principales tareas del filosofar consiste en aclarar qué es lo que se puede decir o pensar con sentido, examinando críticamente las palabras más familiares que usamos y que muchas veces vehiculan pensamientos que nos engañan y que nos hacen malentender las cosas de las que ellos mismos tratan. Un procedimiento del filosofar (si no el procedimento más característico) será, pues, el análisis conceptual por el que llegamos a ver cómo las ideas se convierten en conceptos y qué ideas son aquellas de las que nos tendríamos que deshacer, pues no parecen ser compatibles con aquellos otros conceptos que hemos aclarado críticamente y de los que no podemos prescindir. $\mathrm{El}$ análisis conceptual nos ayuda muchas veces a distanciarnos de pensamientos tradicionales queridos a los que nos hemos acostumbrado y de los que no nos queremos separar. Sirve también para mostrar por vía explicativa cómo muchos de esos pensamientos nos enredan y seducen a pensar sencillamente mal.

Mas la filosofía no solamente consiste en [un] tal análisis conceptual, sino que se propone manifestar y articular aquellas intuiciones y percepciones más fundamentales que, basándonos en la materialidad de nuestras vidas, hemos adquirido y forman parte de nuestro ajuar mental, sin el que no podríamos ser lo que somos.

Una de esas intuiciones fundamentales es nuestra autopercepción como seres libres. Así nos entendemos y ésa parece ser la imagen que tenemos de nosotros mismos. Nos sentimos libres aun cuando sabemos que nuestras acciones, observadas desde el exterior, se ven encuadradas en tramas causales accesibles a un análisis puramente objetivo. Así pues, la tarea de la reflexión filosófica sobre la libertad es una doble tarea. Por una parte, se trata de mostrar cómo es posible ese sentimiento subjetivo de libertad, explicar su razón y su valor. Por otra parte, hay que explicar cómo se pueden conjugar la libertad de los individuos que actúan y el determinismo causal que conduce a pensar que no hay nada sin causa («nihil sine ratione») y, por lo tanto, sin explicación causal.

Desde dentro, se sienten los seres humanos libres cuando hacen la mayoría de las cosas que hacen. Si toman esta o aquella decisión, sienten y piensan que lo hacen libremente sin que nadie ni nada les obligue a hacerlo. En 
teoría, saben que esto no puede ser exactamente así, pero su experiencia subjetiva de las acciones que llevan a cabo, es en la mayoría de los casos una experiencia de libertad práctica.

En una exposición magistral al comienzo de su Ética a Nicómaco (en el capítulo primero, segundo y tercero del tercer libro de dicha obra), Aristóteles desarrolla la idea de que toda acción presupone «voluntariedad» y de que sin esta voluntariedad de nuestros actos la ética como disciplina práctica perdería su objeto material. En efecto, si nuestras acciones estuviesen completamente determinadas y fuesen solamente los efectos de cadenas causales, no podríamos hablar de actos humanos o acciones, sino que tendríamos que hablar de comportamientos de los animales humanos o, en lenguaje escolástico, de actos o acciones «del hombre». Solamente si hay un mínimo de voluntariedad (compatible con y nunca en oposición con determinaciones reales), podemos hablar de acciones intencionales capaces de ser evaluadas moralmente, es decir, de acciones humanas.

Aristóteles excluye una tal «voluntariedad» en dos casos bien concretos: en el caso de ignorancia y en el caso de fuerza mayor. En estos dos casos, debido a que no se da la condición fundamental de la acción humana, es decir, la voluntariedad, no tiene ningún sentido que reaccionemos ante ellos como si de acciones se tratasen: elogiando o censurando el comportamiento en cuestión. El elogio y la censura tienen sentido, si y solamente si hay un mínimo de voluntariedad y, por lo tanto, si se trata de acciones humanas. Si no sé lo que de hecho hago porque pienso que estoy haciendo otra cosa o simplemente mis actos no me son transparentes epistémicamente hablando, es decir, si ignoro lo que de hecho hago, no puedo haberlo hecho en el sentido de haber actuado voluntariamente $y$, por lo tanto, no puedo ser responsable de mi acción. El elogiarme, premiarme, castigarme o censurarme no tendría ningún sentido. Lo mismo pasa, si por fuerza mayor me veo obligado a hacer algo que no quiero hacer. De hecho, lo hago, mas no voluntariamente, sino llevado a ello por causas externas a mi voluntad como pueden ser tempestades o inundaciones, ejemplos naturales que son los normalmente aducidos en estos casos.

Sólo en caso de voluntariedad podemos hablar de acciones que hacemos y de las que somos responsables. Aristóteles sabe, por otra parte, que muchas de nuestras acciones tienen un carácter «mixto». Nosotros somos agentes intencionales al llevarlas a cabo, mas nos encontramos siempre bajo presiones externas que nos determinan de manera considerable. A ello se debe que Aristóteles conciba la voluntariedad como algo gradual y no en términos absolutos de todo o nada. Este gradualismo al que llevan las distinciones aristotélicas al comienzo de su principal obra ética me parece fundamental. Cometeríamos, sin embargo, un gran error si lo interpretásemos en el sentido del incompatibilismo, posición que afirma la incompatibilidad de la libertad humana con toda clase de determinismo causal. 
Las reflexiones y aclaraciones de Aristóteles nos hacen ver en qué consiste la diferencia entre lo que hacemos y lo que simplemente nos pasa o nos ocurre. Además nos manifiestan que aquello que es necesario para que podamos hablar de acciones, es algo de carácter gradual, que se da unas veces más y otras veces menos. Las descripciones aristotélicas coinciden con la imagen que tenemos de nosotros mismos. Por eso podemos afirmar que Aristóteles, a diferencia de muchos naturalismos crudos y burdos, salva conceptualmente nuestra propia autoconcepción de agentes libres y responsables.

Para agentes libres y responsables el futuro está siempre abierto y no fijado de antemano. «Ex ante» es imposible predecir con exactitud cómo tales agentes van a actuar en una determinada situación, pues siempre pueden optar por alguna alternativa realizable para ellos y que ha podido pasar desapercibida para observadores exteriores. Esto no implica en absoluto que «ex post», después de que hayan actuado, observadores exteriores no puedan explicar sus acciones sirviéndose de modelos causales. Mas lo que cuenta realmente es la perspectiva «ex ante» que es una perspectiva de abertura. Por eso tiene sentido que ellos mismos, después de haber actuado, se hagan reproches por haber actuado como han actuado o que se arrepientan de haber hecho lo que hicieron. Tales sentimientos y actitudes prácticas tienen sentido, pues de alguna manera en sus manos, o mejor en su poder, estuvo actuar como actuaron. Al actuar tenían a su disposición alternativas u opciones de acción concretas y determinadas entre las que pudieron escoger y de hecho escogieron. Al actuar se sintieron libres porque veían que existían opciones y alternativas que hubieron podido querer y realizar. Vivieron, pues, en el momento de la acción, su futuro como un futuro abierto, su presente como un momento de decisión no fijado de antemano por nada ni por nadie. El pasado les pareció no tan determinante como otras veces y en otras ocasiones. Sabían que de ellos dependía el futuro, que podían cambiar algo, ser agentes de lo que sucedería. Podrían haber querido, haber preferido, haber decidido, haber hecho algo distinto a lo que en realidad quisieron, prefirieron, decidieron e hicieron.

Ahora bien, todo lo que hasta aquí se ha dicho no puede llevarnos a afirmar que la libertad humana es incompatible con el determinismo causal. Tanto la libertad del actuar como la libertad de la voluntad presuponen condicionamientos, determinaciones y en general contextos causales. Sin éstos, tales libertades no serían comprensibles en absoluto. Los diversos actos por los que podemos optar al actuar son actos determinados, concretos. Puedo hacer esto o lo otro, pero no algo indeterminado.

Para referimos a todo aquello que queremos, al conjunto de nuestros deseos, nos servimos del concepto de la voluntad. Nuestra voluntad es el conjunto de lo que queremos, lo que preferimos, lo que nos interesa. Sin este concepto seríamos incapaces de formular lo que somos cuando queremos y 
actuamos. El concepto de voluntad lo utilizamos para referirnos holísticamente a nuestro querer y para poder desarrollar la idea del actuar, la idea del hacer algo. Nuestra voluntad no es nada misterioso. No es un órgano escondido en alguna parte especial de nuestro organismo, sino que somos nosotros mismos como seres que quieren y tienen una serie de deseos aceptados y queridos que tratan de realizar. El concepto de voluntad nos permite asimismo distinguir entre meros deseos y deseos efectivos en cuanto a la acción: deseos que nos ponen en movimiento, deseos que queremos de hecho realizar. Sin el concepto de voluntad no podemos desarrollar la idea del hacer, de la autoría y de la acción intencionada. La voluntad viene a ser entonces una estructura práctica integrada por deseos, convicciones, reflexiones y disposiciones. La voluntad somos nosotros en tanto que agentes prácticos capaces de actuar para realizar algo que deseamos.

Nuestra voluntad, al igual que nuestros actos, para ser comprensible, para poder ser nuestra voluntad que quiere esto o aquello, tiene que ser una voluntad determinada: «nuestra» voluntad, integrada por deseos específicos, disposiciones, reflexiones y deliberaciones específicas. Una voluntad indeterminada no podría existir, no tendría estructura, sería la voluntad de nadie, ninguna voluntad, algo infundado, casual, no dependiente de nada, incomprensible y arbitrario, en resumidas cuentas: lo contrario de una voluntad.

Nuestra voluntad real no surge del vacío, sino que tiene su historia individual y específica de determinaciones. Como las distintas opciones o alternativas que realizamos al actuar, también la voluntad es algo determinado, algo que pertenece a alguién, inconfundible con otras voluntades, comprensible en su génesis y en su dinámica. Por eso no existe idea más falsa y más confusa que la idea de la libertad incondicionada a la que tan frecuentemente recurrimos cuando pensamos en la libertad, tanto la libertad de la voluntad como la libertad del actuar. La libertad humana exige condicionalidad. Libertad sin condicionalidad es un malentendido, una idea seductora pero errónea y no correcta. Por eso, la libertad no sólo es compatible con la condicionalidad y la determinación, sino que las presupone necesariamente y no sería pensable sin ellas.

Una voluntad sin determinación y condicionalidad es inconcebible. Una voluntad libre sin condicionalidad y determinación es lógicamente imposible, impensable, incomprensible. La libertad de la voluntad tiene que ser, por lo tanto, algo dentro de la condicionalidad y de la determinación, no algo que puede existir cuando se suprime toda condicionalidad y determinación. No es imaginable en qué consistiría una voluntad incondicionalmente libre. Una tal voluntad no se podría dar, no existiría. Sería una voluntad independiente de todo, carente de todo nexo causal, algo completamente abstruso. No dependería del cuerpo de nadie, ni del carácter de nadie, ni de los sentimientos, pensamientos, fantasías y recuerdos de ninguna persona. Sería algo desconectado de todo lo que constituye la personalidad de los indivi- 
duos humanos. Una voluntad incondicionalmente libre sería la voluntad de nadie, no determinada por nada, desconectada de todo, incomprensible e impredecible, una idea sin sentido, una idea inconsistente.

Sin embargo, esa idea tan abstrusa goza de una persistencia considerable en la mente de los seres humanos. A pesar de su imposibilidad lógica, de su impensabilidad, la idea de una voluntad incondicionalmente libre se nos pasa generalmente por la mente siempre que hablamos de libertad. Nuestra experiencia concreta de la libertad, sin embargo, es muy distinta de lo que esa idea de incondicionalidad significa. No obstante, retorna eternamente esa idea estrambótica y esperpéntica, ese espejismo seductor, confundiéndonos y llevándonos a pensar erróneamente.

Nuestra voluntad es siempre una voluntad determinada, condicionada, la voluntad de alguien, nuestra voluntad. La tarea que se presenta a la filosofía de la libertad consiste, pues, en pensar cuál es la diferencia entre libertad y la falta de libertad en el marco de una condicionalidad universal o, refiriéndonos a la voluntad, cuál es la diferencia entre una voluntad condicionada libre y una voluntad condicionada no libre.

\section{La autodeterminación de los individuos libres y sus mecanismos}

La voluntad condicionada libre que tan bien ha sabido describir Peter Bieri en su magistral libro El oficio de la libertad es una voluntad articulada, una voluntad comprendida y una voluntad aprobada, en resumidas cuentas: una voluntad apropiada. La voluntad condicionada libre no se tiene sin más ni más, sino que se adquiere en un proceso de apropiación penoso y laborioso, en el que se trata de averiguar lo que realmente se quiere, comprender cómo se llega a querer lo que se quiere y se evalúa críticamente lo querido para aceptarlo o para rechazarlo y querer en su lugar algo distinto.

La libertad verdadera, la única posible y real para los individuos humanos, se gana con esfuerzo y trabajo. Es una libertad que se puede perder y es una libertad que admite grados, pues se puede ser más o menos libre, dependiendo del resultado del proceso de apropiación. Es una libertad que consiste en identificarse con los deseos que uno tiene, después de haberlos identificado claramente, después de haberlos comprendido en su génesis y funcionamiento y después de haberlos evaluado adecuadamente. La libertad presupone por ello que los individuos sepan realmente lo que quieren. Lleva a una sinceridad con respecto de lo que uno quiere y a una superación de toda clase de autoengaño por el que normalmente nos solemos atribuir deseos que no tenemos o solemos ignorar los deseos que realmente tenemos. Presupone además la comprensión de lo que se desea, es decir, la reconstrucción de lo deseado como algo que nos pertenece y que se ve integrado en la dinámica de nuestras vidas. De esta manera se convierten los deseos en par- 
tes esenciales de nuestras vidas, perdiendo así su existencia extraña y amenazadora de nuestra libertad. Esta comprensión puede incluso llevar en algunos casos a que desaparezca el conflicto de deseos que nos abrumaba y en otros a la superación de las así llamadas crisis existenciales. Por último, la libertad promueve el juicio valorativo que se enfrenta con nuestros deseos espontáneos, llevándonos a su examen crítico.

La libertad determinada y real de los seres humanos es por supuesto algo más que una empresa teórica de articulación, comprensión y valoración. La libertad determinada y real de los seres humanos es de hecho una realidad práctica de autodeterminación, compleja y diversificada que se sirve de muchos mecanismos y procedimientos que llevan todos a que, en un mundo de condicionalidad, pueda existir aquello que, a primera vista, no parece ser compatible con esa condicionalidad y determinación. Sin ninguna pretensión de exhaustividad me propongo mencionar a continuación algunos de esos mecanismos y procedimientos en los que consiste de hecho nuestra libertad real en el mundo empírico y determinado, el único mundo existente al que pertenecen nuestras vidas y en el que puede tener éxito o fracasar nuestra empresa de la libertad.

Clásico es el mecanismo de autodeterminación que ejemplifica Ulises, tan explotado por Jon Elster entre otros muchos libros en su Ulysses Unbound. Ulises quiere disfrutar del canto de las sirenas. Sabe también que si no toma ciertas medidas esa fruición significa su fin, por lo que, anticipando la posible catástrofe futura, pide a sus compañeros de viaje que le aten ahora al mástil de la nave e ignoren sus ruegos y gritos cuando en el futuro se vea seducido por el irresistible canto. Este caso, muchas veces interpretado como símbolo de la racionalidad limitada propia de los seres humanos, lo tomo aquí como paradigma de autodeterminación que permite, limitando la propia libertad futura en el presente a través de un acto de libertad, abrir un campo de acción en el que es posible tener ciertas experiencias de libertad dentro de un marco restrictivo autoimpuesto. Ulises, ejemplifica, pues una doble libertad: la libertad de autodeterminación en el presente, por la que elimina opciones y alternativas en el futuro, y la libertad vivenciable bajo los condicionamientos que se autoimpuso. Al autolimitarse realiza su libertad en el presente. Al autolimitarse abre un campo de acción restringido para el futuro en el que va a poder actuar, disfrutar y sobrevivir como sujeto sentiente.

Todos los casos de autolimitación funcionan de acuerdo con una misma lógica. Se salvan opciones y alternativas de acción limitando el campo de acción o eliminando posibles opciones y alternativas. Esto lo hace Ulises y lo hacemos cada uno de nosotros cuando nos autoimponemos normas y reglas de acuerdo con las cuales actuamos. También lo hacen los políticos profesionales cuando ponen en manos de bancos nacionales la politica monetaria del país perdiendo ellos mismos su influencia inmediata sobre esa política monetaria para poder concentrarse en otros temas y asuntos. 
Las constituciones políticas surgen de esta misma dinámica de autolimitación que elimina opciones creando así posibilidades de acción dentro de los marcos acordados. Una constitución es de hecho el marco de acción que se da una cierta colectividad limitando su libertad de acción y posibilitando al mismo tiempo libertad real de acción.

En el terreno de la producción artística también lleva la autolimitación a la generación de creatividad y de toda una serie de innovaciones. Conocido es el grupo francés de vanguardia «Oulipo», que se propuso crear pequeñas novelas utilizando sólo la vocal «e»o, por el contrario, prescindiendo de esa misma vocal. Todo poema es, en términos generales, un texto autolimitado y autodeterminado por reglas (por ejemplo, la rima). La fijación de un presupuesto implica asimismo una limitación para producciones artísticas permitiendo el comienzo de la obra. En todos estos casos se ve cómo las restricciones no llevan a eliminar la actividad creadora de innovación en cuestión, sino que, por el contrario, la facilitan. Demasiadas opciones no siempre conducen a una mayor actividad, e incluso pueden paralizar la creatividad, consistiendo esta creatividad muchas veces en la eliminación de las muchas posibilidades y en la concentración en unas pocas.

Ciertos afectos o sentimientos permiten a menudo actuar precisamente cuando el agente se ve incapaz de decidirse por una de las posibles alternativas. Dejándose llevar por un sentimiento o una emoción particular, privilegia entonces el sujeto en cuestión una alternativa concreta y consigue decidir en una situación en la que la decisión parecía imposible, lo que pone de manifiesto que la determinación que supone el estado emotivo favorecido no solamente no impide la actividad libre, sino que, por el contrario, la facilita y la hace posible.

En la teoría de la elección racional se ha analizado con frecuencia el fenómeno de la adaptación racional de las preferencias a lo realizable, un fenómeno popularmente conocido con el nombre del «síndrome de las uvas verdes». El fenómeno consiste en querer lo que se puede y deshacerse de aquellas preferencias cuya realización se presenta por diversas razones en la situación respectiva de acción o de decisión como muy difícil y costosa si no prácticamente imposible. En ese caso es aconsejable olvidarse racionalmente de lo inalcanzable, para posibilitar lo factible.

Todos estos fenómenos, en cuyos pormenores no quiero entrar, demuestran que la actividad libre de los seres humanos muchas veces no presupone una proliferación de posibilidades, opciones y alternativas, sino que surge, por el contrario, a partir de procesos libres de autodeterminación y autolimitación, es decir, bajo condiciones específicas de actuación que los agentes se autoimponen, no abandonando así el marco de la condicionalidad universal, sino configurándolo autónomamente de una manera específica e individual. La autoría de los seres humanos, en la que consiste su libertad efectiva de acción, tiene siempre sus condiciones de existencia y desarrollo. Una tal 
autoría se da sólo condicionalmente. Presupone condicionalidad e implica una configuración activa y voluntaria de esa misma condicionalidad. Autoría y condicionalidad no se contradicen. Más bien se presuponen en el caso del animal racional. Sin condicionalidad la autoría humana sería impensable en teoría e irrealizable en la práctica.

\section{BIBLIOGRAFÍA}

ARISTÓTELES (2001): Ética a Nicómaco (introducción, traducción y notas de José Luis Calvo Martínez), Alianza Editorial, Madrid.

BIERI, P. (2002): El oficio de ser libre, Ariel, Barcelona.

ELSTER, J. (2000): Ulysses Unbound. Studies in Rationality, Precommitment, and Constraints, CUP, Cambridge. 